\title{
Wyznaczanie rozkładu szczelin w formacjach typu shale gas na podstawie azymutalnych pomiarów sejsmicznych
}

\begin{abstract}
W artykule została zaprezentowana metodyka wyznaczania rozkładu szczelin i ich azymutów dla dwóch horyzontów sejsmicznych odpowiadających stropowi ogniwa Jantaru i formacji z Sasina, tj. poziomów zbiornikowych typu shale gas, na podstawie azymutalnych pomiarów sejsmicznych 3D. Fala sejsmiczna propagująca przez ośrodek geologiczny uzyskuje wyższą prędkość, przechodząc wzdłuż systemu spękań, a niższą prostopadle do nich. Wykorzystanie tego zjawiska umożliwia przeprowadzenie analiz zmian amplitud względem różnych kierunków (azymutów) zapisu sejsmicznego, pozwalając na określenie stopnia zmienności parametrów sprężystych w układzie HTI (horizontal transverse isotropy). Wyznaczony w ten sposób stopień zmienności umożliwia określenie wielkości oraz kierunków rozkładu szczelin rozpatrywanego ośrodka geologicznego. Stopień rozpoznania intensywności oraz orientacji kierunków spękań (szczelin) jest szczególnie ważny w projektowaniu otworów poziomych oraz w optymalizacji procesów eksploatacji węglowodorów ze złoża.
\end{abstract}

Słowa kluczowe: sejsmika azymutalna, aproksymacja, szczelinowatość, shale gas.

\section{Determining distribution of fractures in shale gas formations based on azimuthal seismic survey}

This article presents results of a methodology of determining the distribution of fractures and their azimuths for two seismic horizons corresponding to the tops of Jantar member and Sasino formation, i.e. the levels of shale gas type reservoir, based on azimuth 3D seismic data. Seismic wave propagating through the geological medium achieved higher velocity going along the system fracture and a lower perpendicular to them. Use of this phenomenon makes it possible to carry out analyzes of changes in amplitude, with respect to different directions (azimuths) of seismic record, allowing to determine the degree of variability of elastic parameters in a HTI (Horizontal Transverse Isotropy). The specified degree of variation makes it possible, to determine the size and direction of fractures distribution in the geological medium. The degree of the intensity and orientation directions of cracks (fractures), is particularly important in the design of horizontal wells and optimizing the exploitation processes of hydrocarbons from the reservoir.

Key words: azimuthal seismic, approximation, fractures, shale gas.

\section{Wstęp}

Stopień intensywności spękań i ich azymuty mają szczególne znaczenie w analizie złóż węglowodorów występujących w utworach węglanowych, jak również w cienkowarstwowych skałach klastycznych. Rozmieszczenie i układ szczelin jest wynikiem oddziaływań naprężeń, jakie występowały podczas kształtowania się procesów geologicznych $[6,8]$.

Szczeliny odgrywają ważną rolę w akumulacji oraz transporcie węglowodorów. Stopień rozpoznania intensywności oraz orientacji kierunków spękań (szczelin) jest szczególnie ważny w projektowaniu otworów poziomych mających udostępnić złoża o charakterze niekonwencjonalnym (tight, shale), jak również w optymalizacji procesów eksploatacji węglowodorów ze złoża $[3,4,5]$.

Układ szczelin w przestrzeni okołootworowej może być pomierzony bezpośrednio przy pomocy pomiarów geofizyki otworowej (np. skaner akustyczny) lub poprzez wizualną 
ocenę rdzenia wiertniczego. Pośrednio analizy spękań można dokonać na podstawie analiz zmian parametrów sprężystych fal podłużnych PP (anizotropia VTI) oraz fal poprzecznych PS (anizotropia HTI), przy użyciu wieloazymutalnych pomiarów PPS $3 \mathrm{C}[1,2]$.

Jednak w przypadku rozpoznawania orientacji szczelin na znacznie większym obszarze stosuje się standardowe badania sejsmiczne 3D, które stanowią użyteczną podstawę do analizy spękań, wykorzystując czasowy przebieg fali sejsmicznej PP w ośrodku geologicznym. Standardowe pomiary sejsmiczne 3D po przetwarzaniu wstępnym są azymutalnie sortowane na poszczególne sektory, a następnie każdy niezależny sektor jest poddawany dalszym procedurom przetwarzania. Ostateczne wolumeny sektorowe stanowią podstawę do wykonywania analiz spękań oraz szczelinowatości.

W praktyce można wyróżnić trzy metody umożliwiające identyfikację szczelin na podstawie analiz fal PP [8]:

1) analizy prędkości z offsetem NMO (NMO velocity method),

2) analizy resztkowe z uwzględnieniem NMO (residual moveout method),

3) analizy amplitudowe (amplitude method).

W artykule została zaprezentowana metodyka identyfikacji spękań w utworach łupkowych na podstawie analiz zmienności amplitud z azymutem wykonanych na sześciosektorowych danych sejsmicznych pochodzących $\mathrm{z}$ rejonu północnej Polski.

\section{Metodyka aproksymacji parametrów sprężystych}

Do aproksymacji rozkładu amplitud na podstawie sektorowych danych sejsmicznych wykorzystano program ANISO-HTI, będący własnością INiG - PIB.

Spośród wielu metod umożliwiających wyznaczenie zmienności parametrów sprężystych przy użyciu sektorowych danych sejsmicznych wykorzystano zaimplementowaną formułę (1) do programu ANISO-HTI, której zadaniem jest dopasowanie krzywej cosinus do zbioru azymutalnych wartości odpowiadających danej komórce (bin) - rysunek 1 [7]:

gdzie: $\quad y_{k}(\alpha)=V_{k, s r}+A_{k} \cdot \cos \left(2 \cdot \alpha-2 \delta_{k}\right)$

$k$ - numer komórki/rekordu,

$\alpha$ - kąt (azymut kąta padania i odbioru propagujących fal sprężystych),

$V_{k, s r}$ - wartość średnia amplitudy dla danej komórki,

$A_{k}$ - amplituda (pierwszy parametr dopasowania),

$\delta_{k}$ - faza (drugi parametr dopasowania).

Zakresy wielkości $A_{k} \in\left[0, A_{k, \max }\right]$ i $\delta_{k} \in[0, \pi]$ wyznaczają przestrzeń parametryczną dla aproksymacji. Do optymalizacji wartości amplitudy w komórce wykorzystano normę Czebyszewa (2) oraz normę średniokwadratową (3):

$$
H_{k}^{(1)}=\frac{1}{n} \sum_{i=1}^{n}\left|f\left(\alpha_{i}\right)-V_{k, s r}-A_{k} \cos \left(2 \cdot \alpha_{i}-2 \delta_{k}\right)\right|
$$

$$
H_{k}^{(2)}=\frac{1}{n} \sqrt{\sum_{i=1}^{n}\left|f\left(\alpha_{i}\right)-V_{k, s r}-A_{k} \cos \left(2 \cdot \alpha_{i}-2 \delta_{k}\right)\right|^{2}}
$$

gdzie:

$n$ - liczba danych dla danej komórki/rekordu.

Po wyznaczeniu wszystkich wartości $H_{k}$ dla danej komórki - wyszukiwana jest wartość najmniejsza (spełniająca warunek aproksymacji) dla minimalnej wartości normy, dająca największą wartość amplitudy (optymalizacja amplitudy). Innymi słowy, metoda ta wyszukuje taką wartość dla danej komórki, która jest najmniejsza i minimalizuje błąd dopasowania funkcji cosinus do zbioru punktów.

Program ANISO-HTI (rysunek 2) posiada wiele użytecznych funkcji, które umożliwiają elastyczną wizualizację oraz selekcję wyników obliczeń. Wyniki aproksymacji mogą być zapisywane w postaci graficznej oraz w różnych opcjach formatu ASCII: extended, short, for PETREL format (zgodny ze standardem formatu Petrel).

Wynikowy plik aproksymacji parametrów sprężystych w formacie ASCII może zostać zaimportowany do systemu Petrel, umożliwiając graficzną wizualizację zmienności amplitud/prędkości względem azymutu i intensywności szczelin (długość prostokąta) wczytanego parametru.

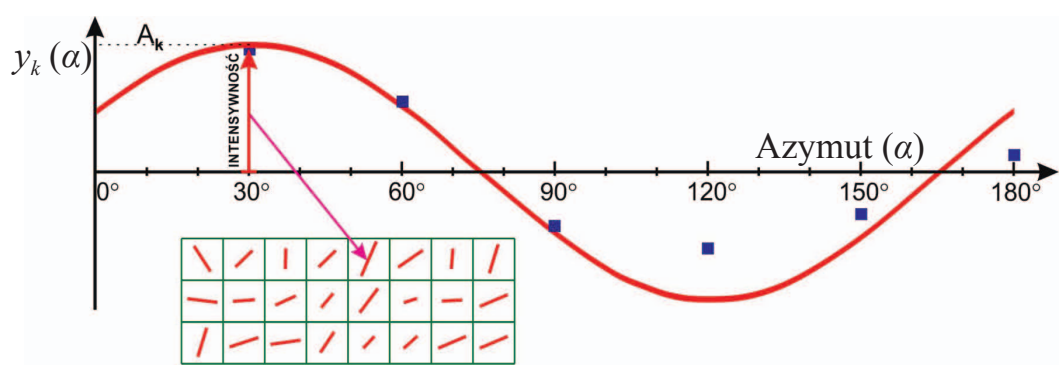

Rys. 1. Dopasowanie funkcji cosinus do azymutalnych wartości amplitud sektorowych danych sejsmicznych. Maksymalna lub minimalna wartość na osi rzędnych wyznacza poziom intensywności spękań, a wartość na osi odciętych określa kierunek (azymut) spękań 

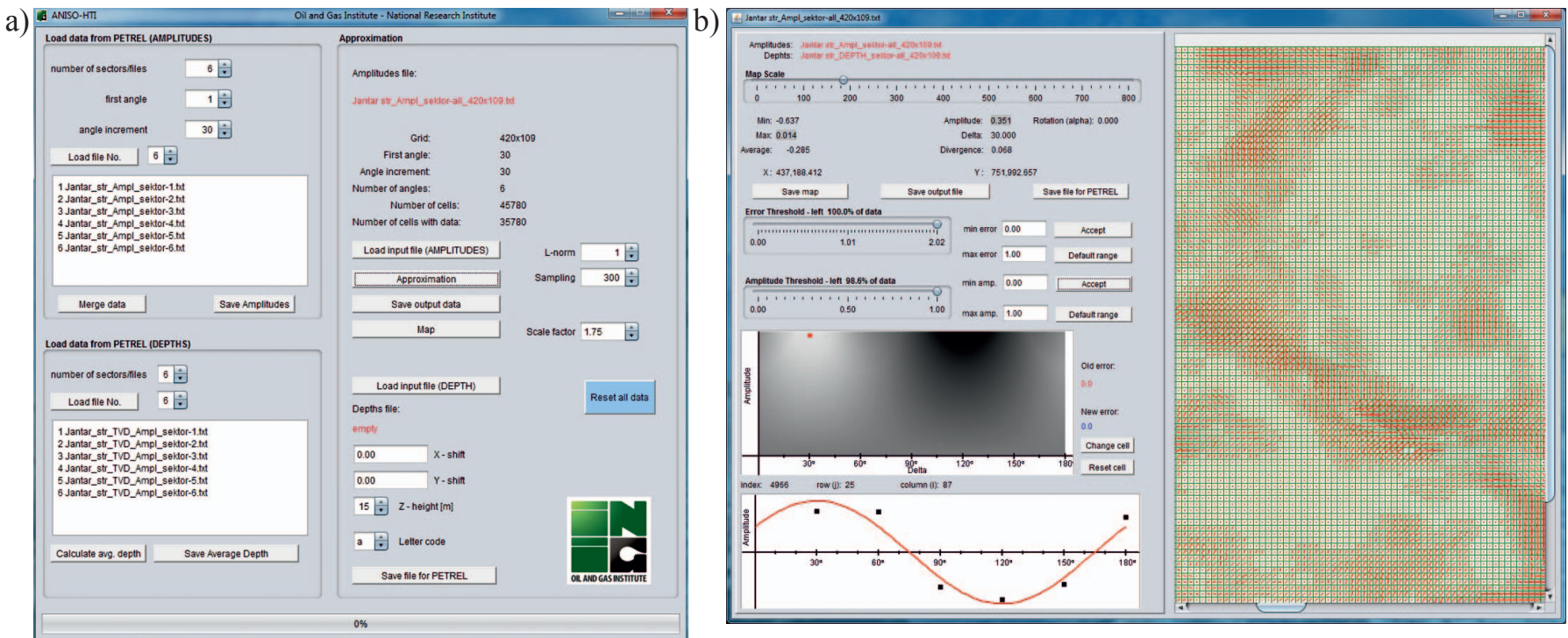

Rys. 2. a) Widok głównego okna programu ANISO-HTI, b) graficzna wizualizacja parametrów aproksymacji oraz intensywności i azymutów spękań w poszczególnych binach

\section{Wyznaczanie szczelinowatości na podstawie danych sejsmicznych}

Obszar badań sejsmicznych 3D i pomiarów geofizycznych użytych do wyznaczania zmienności rozkładu szczelin pochodzi z północnego obszaru Polski (rysunek 3). Na podstawie odwiertów W-1-W-4 określono profil litostratygraficzny, który reprezentowany jest przez utwory kambru, ordowi$\mathrm{ku}$, syluru, cechsztynu, triasu, jury, kredy oraz kenozoiku.

Metodyka określenia intensywności i rozkładu szczelin zastosowana została na bazie danych sejsmicznych 3D po migracji głębokościowej pełnego azymutu (CRAM), wykonanej w pakiecie ES360 firmy Paradigm przez Geofizykę Toruń. Przedmiotowe dane zostały podzielone na sześć sektorów azymutalnych: $0 \div 30^{\circ}, 30 \div 60^{\circ}, 60 \div 90^{\circ}, 90 \div 120^{\circ}, 120 \div 150^{\circ}$ i $150 \div 180^{\circ}$. Główny cel badania zmienności rozkładu szczelin był związany z utworami występującymi w ogniwie Jantar oraz formacji Sasino, które potencjalnie mogą stanowić poziomy zbiornikowe typu shale gas.

Utwory ogniwa Jantaru reprezentowane są przez serię iłowców i mułowców z bardzo licznymi graptolitami. Formacja z Sasina zbudowana jest głównie z czarnych łłowców z liczną fauną graptolitów. Obydwa ogniwa litostratygraficzne rozdziela formacja margli i iłowców z Prabut.

Dowiązanie danych otworowych i stratygraficznych do horyzontów sejsmicznych wykonano, opierając się na obliczonym sejsmogramie syntetycznym. W wyniku dopaso-

b)

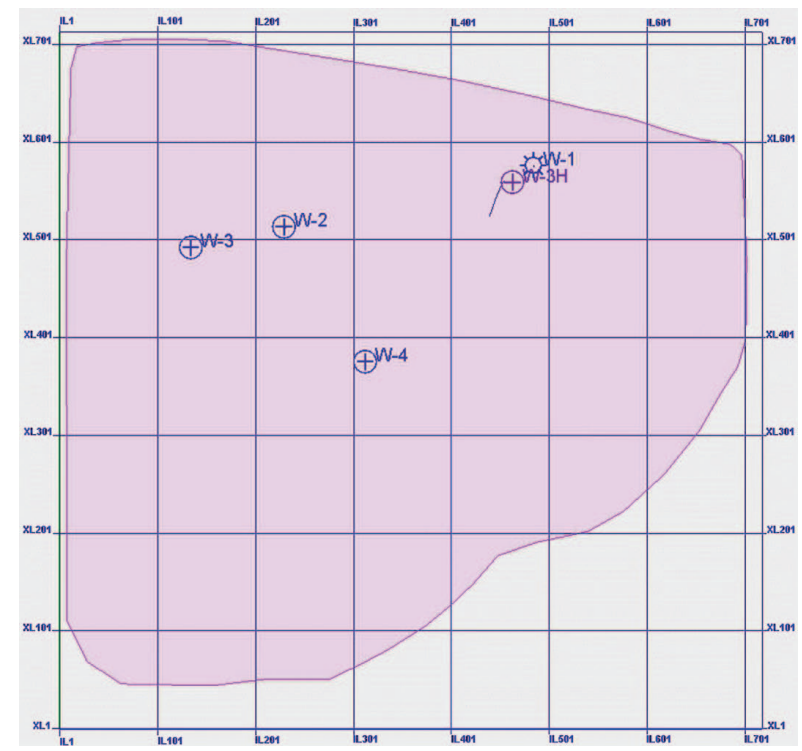

a)

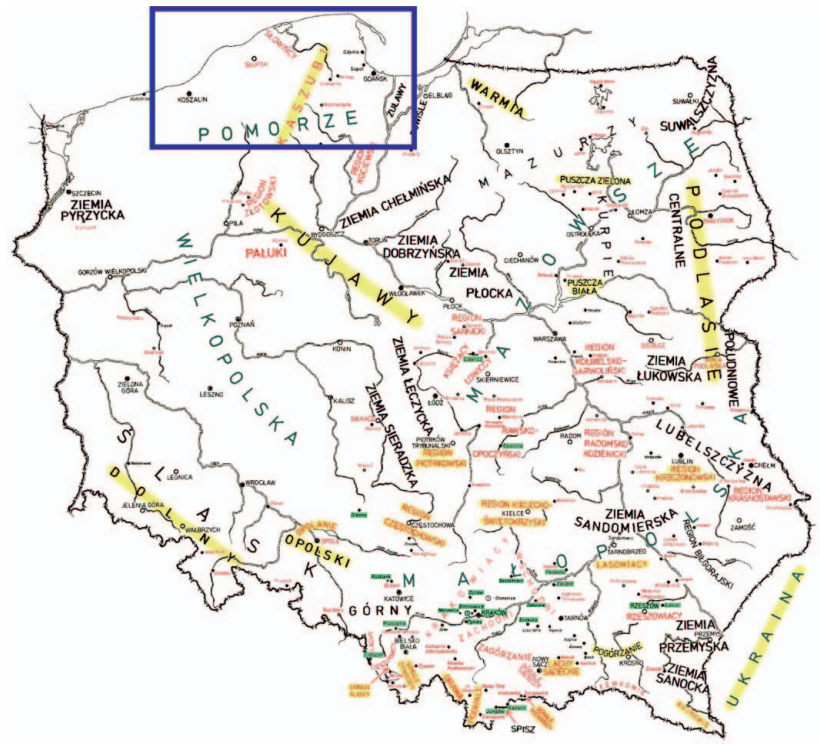

Rys. 3. a) Lokalizacja obszaru badań, b) obszar zdjęcia sejsmicznego 3D wraz z lokalizacją odwiertów wykorzystanych w opracowaniu 


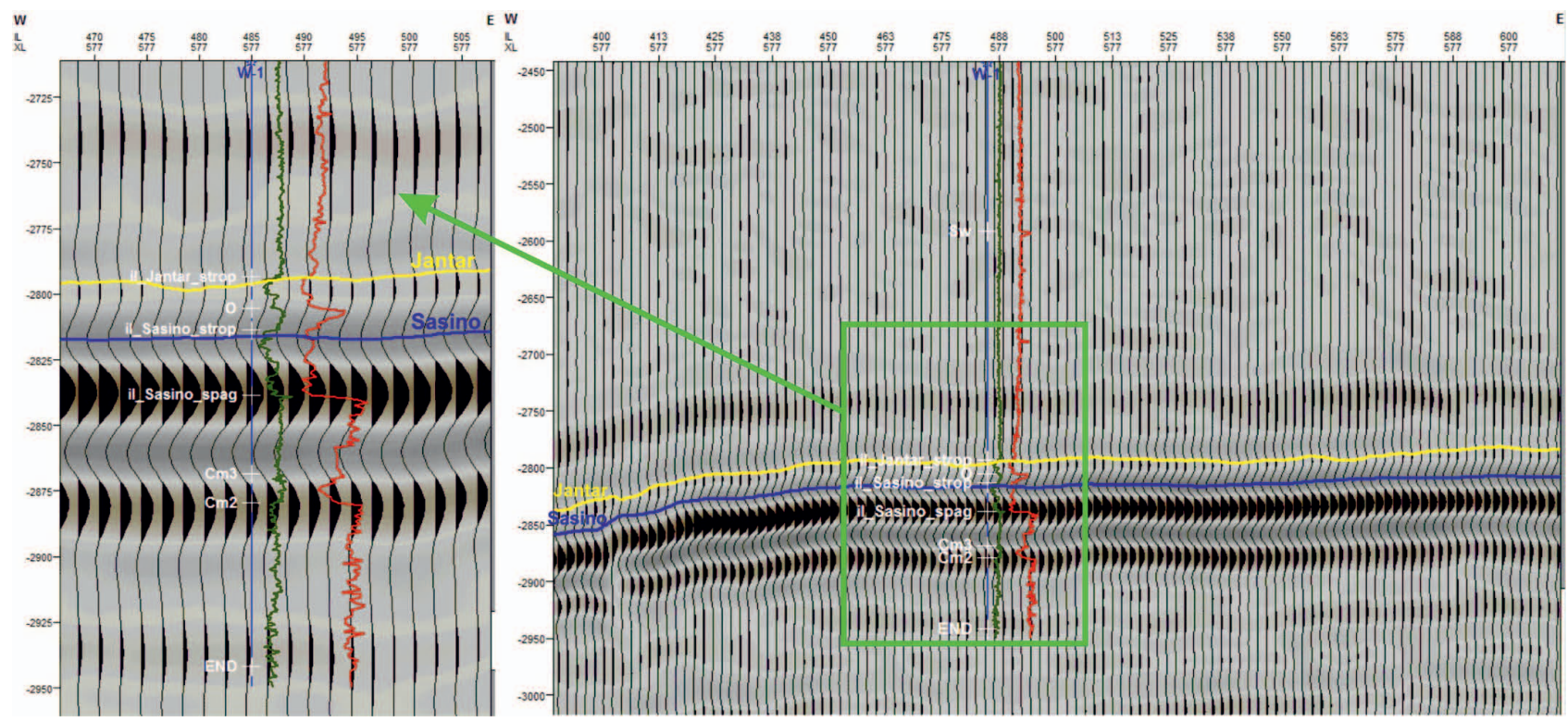

Rys. 4. Interpretacja stropów Jantaru i Sasina w pozycji otworu W-1 na danych sejsmicznych 3D - sektor $3\left(60 \div 90^{\circ}\right)$

wania wyznaczono granicę sejsmiczną dla stropu Jantaru, której wartość amplitudy wynosiła zero, natomiast dla stropu formacji Sasino przyjęto maksimum ujemne amplitudy (rysunek 4).

Interpretacja powyższych horyzontów została wykonana dla sześciu sektorów zdjęcia sejsmicznego 3D. Uzyskano sześć map strukturalnych dla horyzontu Jantar oraz sześć dla Sasina. Wartości amplitud wyinterpretowanych horyzontów zostały wyekstrahowane z sektorowych zdjęć 3D do plików formatu ASCII, które stanowiły podstawę aproksymacji szczelin w programie ANISO-HTI (rysunek 5).

Uzyskane mapy rozkładu amplitud dla sześciu sektorów azymutalnych: $0 \div 30^{\circ}, 30 \div 60^{\circ}, 60 \div 90^{\circ}, 90 \div 120^{\circ}, 120 \div 150^{\circ}$ i $150 \div 180^{\circ}$ dla horyzontu Sasino posiadają wyraźne zmiany wartości, które wynikają z anizotropii prędkości ośrodka, co uwzględnione jest w przetwarzaniu sektorowym (rysunki 5a', b', c').

Wykorzystując fakt, iż fala sejsmiczna rozchodzi się szybciej wzdłuż systemu spękań aniżeli prostopadle do nich, na podstawie analiz zmian amplitud względem różnych azymutów zapisu sejsmicznego można określić stopień anizotropii w układzie HTI (horizontal transverse isotropy) analizowanego horyzontu. Wyznaczony stopień zmienności parametrów sprężystych (amplitudy, prędkości) umożliwia określenie wielkości oraz kierunków rozkładu szczelin dla rozpatrywanego horyzontu sejsmicznego ośrodka geologicznego. Rozdzielczość metody jest zależna od rozmiaru binu.

Do obliczeń rozkładu szczelin na podstawie wyekstrahowanych amplitud dla horyzontów Jantar oraz Sasino, pochodzących z sektorowych danych sejsmicznych 3D, wykorzystano program ANISO-HTI. Wielkość binu danych sektorowych wynosiła $20 \mathrm{~m} \times 20 \mathrm{~m}$.
Po wykonaniu kilku testów aproksymacji amplitud dla horyzontów Jantar oraz Sasino okazało się, że metoda optymalizacji amplitudy Czebyszewa jest dokładniejsza niż norma średniokwadratowa. Wobec powyższego w obliczeniach zastosowano normę optymalizacji Czebyszewa.

Otrzymany wynik sektorowych aproksymacji amplitud dla horyzontów Jantar oraz Sasino w programie ANISO-HTI był podstawą graficznej wizualizacji rozkładu intensywności oraz kierunkowej zmienności szczelin w programie Petrel (rysunki 6, 7).

W przypadku aproksymacji amplitud obrazujących intensywność występowania szczelin dla horyzontu Jantar (rysunek 6a) widać, że intensywność ta jest znacznie mniejsza niż dla horyzontu Sasino (rysunek 7a). Intensywność rozkładu szczelin dla horyzontu Jantar jest najwyższa na obszarze południowo-wschodnim, natomiast dla horyzontu Sasino na obszarze północno-zachodnim.

W celu graficznego zobrazowania kierunków oraz intensywności szczelin wybrano do analizy fragmenty obszaru aproksymacji amplitud horyzontów Jantar i Sasino obejmujące otwory W-1, W-2H oraz W-3H (rysunek 6b, 7b). Intensywność szczelin dla horyzontu Jantar (rysunek 6b) jest znacznie mniejsza niż dla horyzontu Sasino (rysunek 7b). W obrębie otworu pionowego W-1 w przypadku horyzontów Jantar oraz Sasino występuje układ szczelin o kierunku wschód-zachód o znacznej długości, co uwidocznione jest w postaci długości prostokątów.

Istotna różnica $\mathrm{w}$ intensywności rozkładu szczelin pomiędzy horyzontem Jantar a Sasino widoczna jest dla otworu poziomego $\mathrm{W}-2 \mathrm{H}$. Na trajektorii tego otworu dla horyzontu Sasino rozmiar szczelin jest duży, dochodzi do $17 \mathrm{~m}$, i są one zorientowane względem kilku kierunków: wschód-za- 
a)

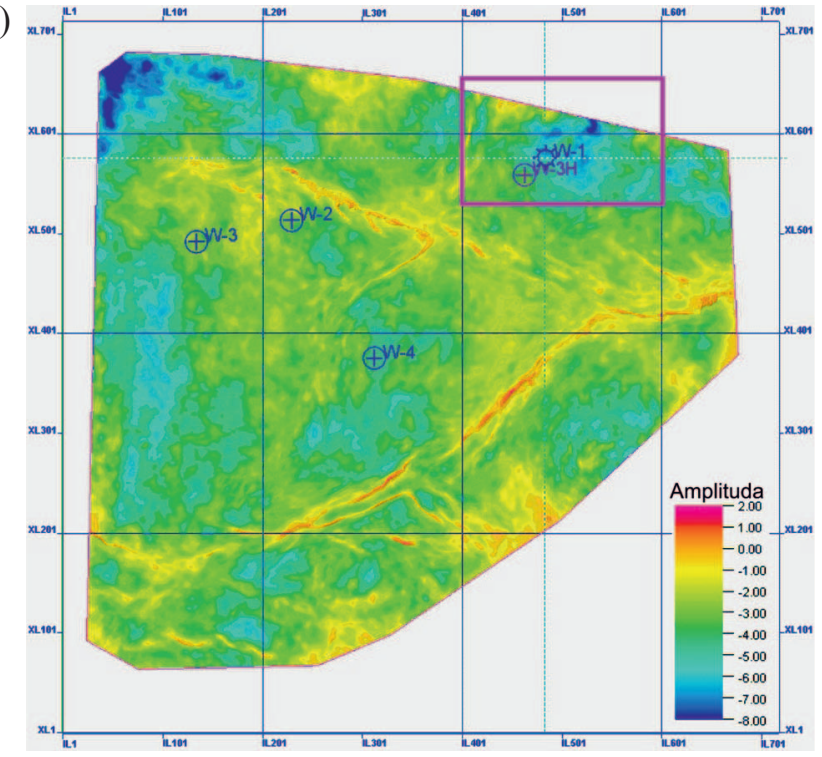

b)

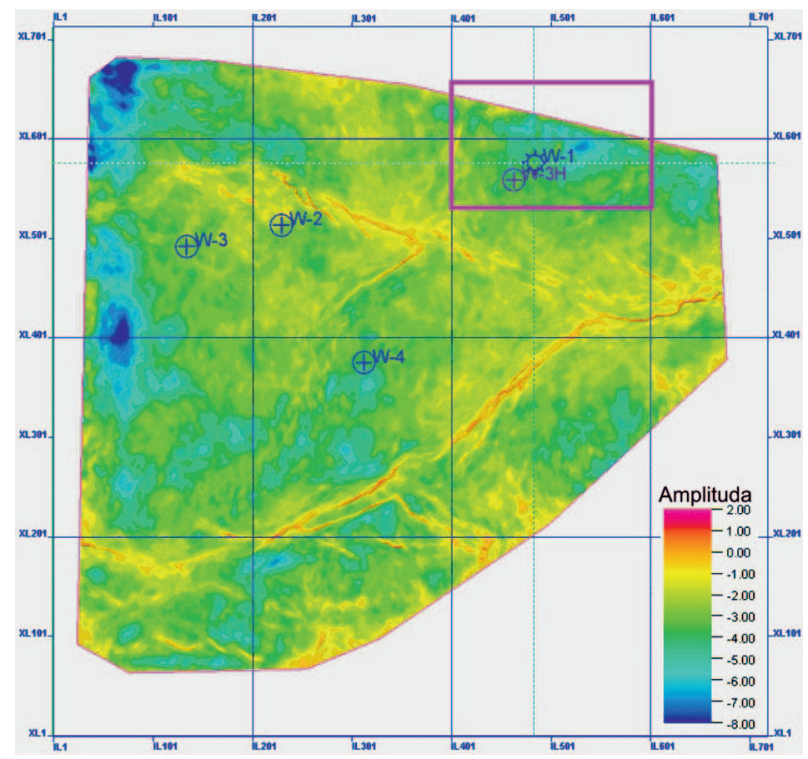

c)
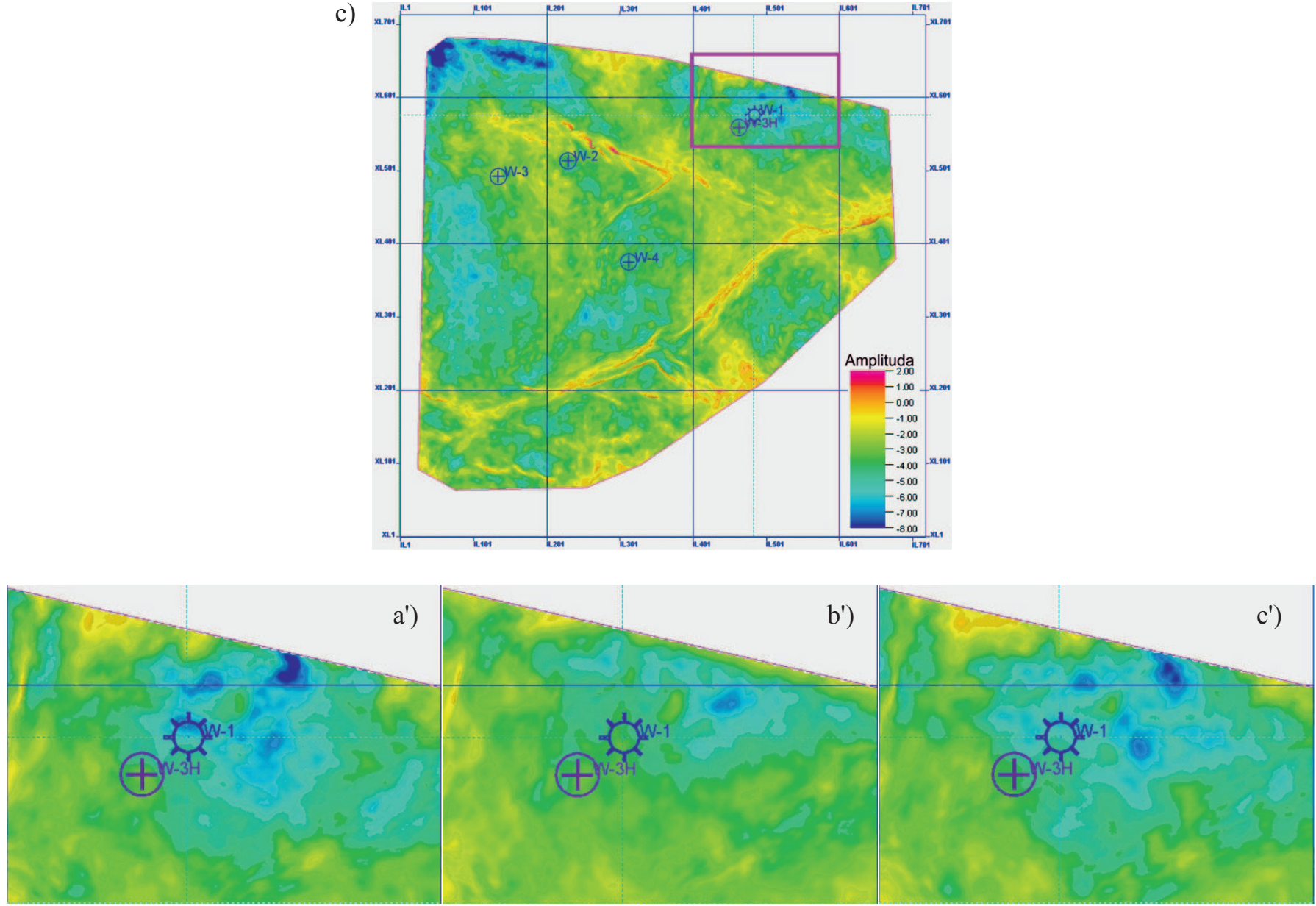

Rys. 5. Wyekstrahowane mapy amplitud zdjęcia sejsmicznego 3D dla horyzontu Sasino dla: sektora I $\left(0 \div 30^{\circ}-\mathrm{a}, \mathrm{a}^{\prime}\right)$, sektora III $\left(60 \div 90^{\circ}-\mathrm{b}, \mathrm{b}^{\prime}\right)$, sektora VI $\left(150 \div 180^{\circ}-\mathrm{c}, \mathrm{c}^{\prime}\right)$

chód (część I), południowy zachód-północny wschód oraz wschód-zachód (część II), wschód-zachód oraz północny zachód-południowy wschód (część III). Natomiast w części II i III trajektorii otworu W-2H dla horyzontu Jantar wyraźnie zaznacza się obniżenie intensywności występowania szczelin.
W przypadku otworu poziomego W-3H uwidacznia się wyższy poziom zeszczelinowania ośrodka geologicznego dla horyzontu Sasino niż Jantar. Układ szczelin przyjmuje dwa zasadnicze kierunki: w części I północny zachód-południowy wschód, a w części II - kierunek północ-południe. 
a)

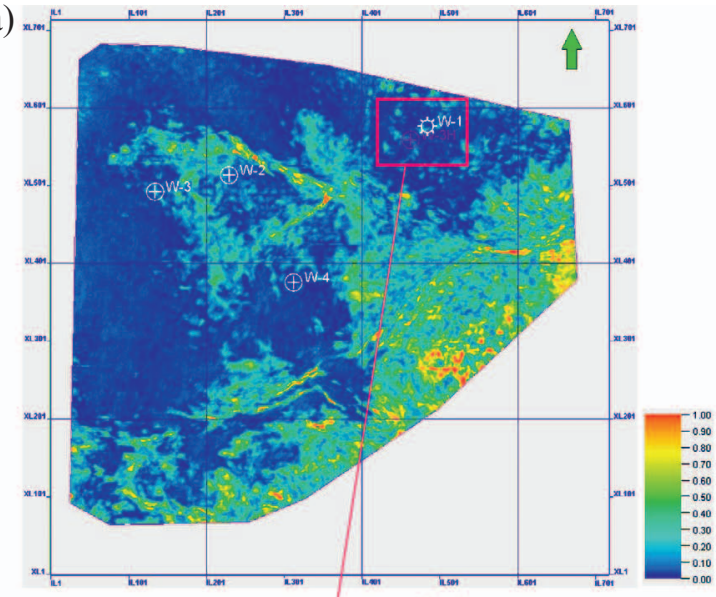

b)

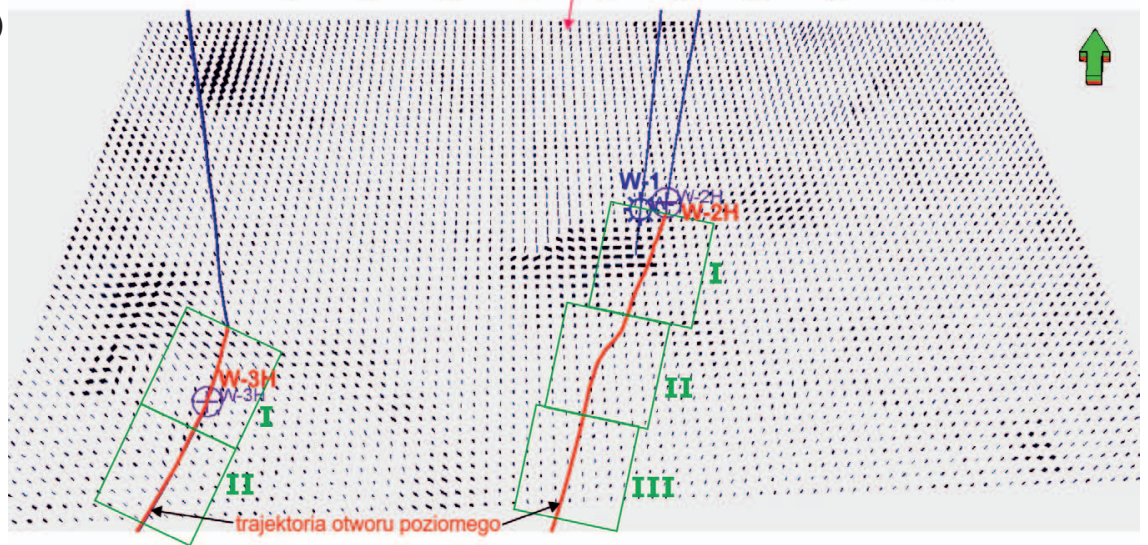

Rys. 6. Wynik aproksymacji amplitud dla horyzontu Jantar, a) intensywność występowania szczelin, b) azymutalny rozkład szczelin w obszarze występowania otworów: pionowego W-1 oraz poziomych W-2H i W-3H

a)

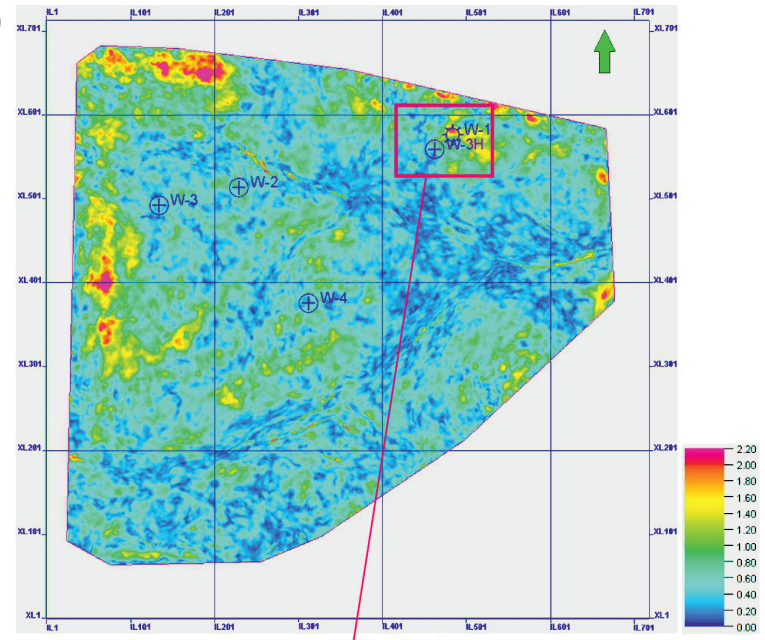

b)

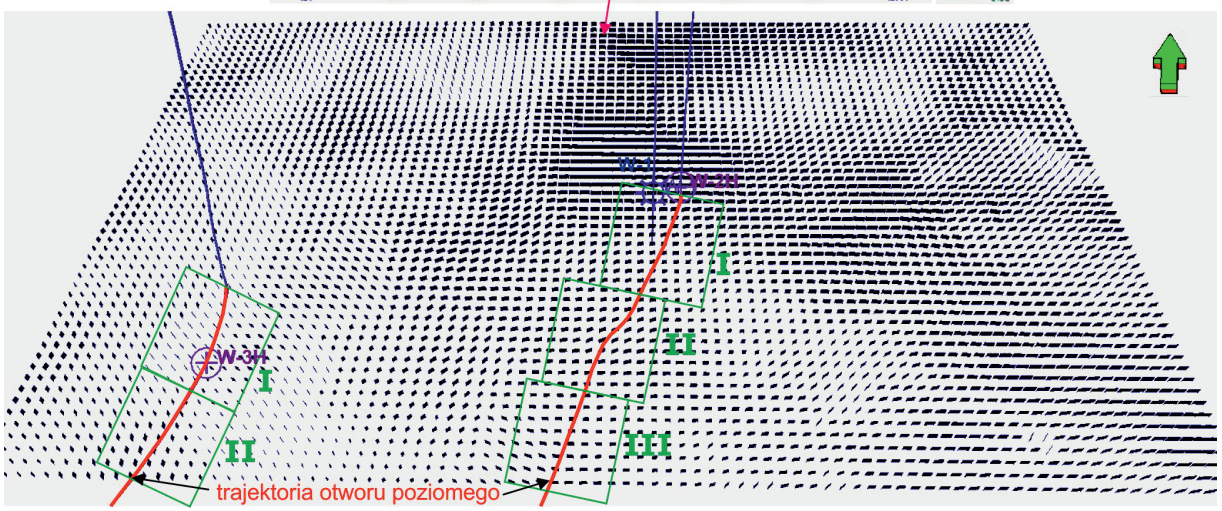

Rys. 7. Wynik aproksymacji amplitud dla horyzontu Sasino, a) intensywność występowania szczelin, b) rozkład szczelin w obszarze występowania otworów: pionowego W-1 oraz poziomych W-2H i W-3H 


\section{Podsumowanie i wnioski}

Przedstawiona metodyka aproksymacji parametrów sprężystych na podstawie azymutalnych analiz sejsmicznych HTI bazuje na istniejących rozwiązaniach, które zostały zaimplementowane do programu ANIZO-HTI, stanowiącego własność INiG - PIB.

Uzyskane wyniki intensywności rozkładu szczelin i ich azymutów zostały zaprezentowane dla dwóch horyzontów sejsmicznych: Jantar i Sasino, poziomów zbiornikowych typu shale gas. Aby zweryfikować otrzymane wyniki rozkładu szczelinowa- tości, należy je porównać z danymi otworowymi, np. z wynikami profilowania sondą XRMI, obrazującymi układ i azymut szczelin. Na aktualnym etapie opracowania autorzy nie uzyskali zgody na prezentację wyników interpretacji szczelinowatości z wykorzystaniem sondy XRMI w otworach W-1-W-4.

Rezultaty rozkładu szczelinowatości otrzymane na podstawie zastosowanej metodyki obliczania dają podstawę do jej wdrożenia w przyszłych pracach poszukiwawczych w polskim górnictwie naftowym.

Prosimy cytować jako: Nafta-Gaz 2016, nr 12, s. 1011-1017, DOI: 10.18668/NG.2016.12.01

Artykuł nadesłano do Redakcji 3.11.2016 r. Zatwierdzono do druku 18.11.2016 r.

Artykuł powstał na podstawie badań zrealizowanych w ramach projektu pt. Metodologia wyznaczania sweet spotów na podstawie własności geochemicznych, petrofizycznych, geomechanicznych w oparciu o korelację wyników badań laboratoryjnych z pomiarami geofizycznymi i model generacyjny 3D - dofinansowanego przez Narodowe Centrum Badań i Rozwoju w ramach programu Blue Gas - Polski Gaz Łupkowy. Nr umowy: BG1/MWSSSG/13.

\section{Literatura:}

[1] Bartoń R.: Role of VSP measurement in investigation of anisotropy of geological medium. Galperin Readings 2011, Moscow CGE 24-28 October 2011.

[2] Bartoń R.: Wyznaczanie kierunkowych zmian prędkości fal poprzecznych $w$ strefie okolootworowej na podstawie azymutalnych pomiarów PPS 3C. Nafta-Gaz 2014, nr 8, s. 483-492.

[3] Buczek T., Wilk A.: Zastosowanie azymutalnych analiz sejsmicznych do poszukiwań złóż typu shale gas. [W:] Geopetrol 2012: Nowoczesne technologie pozyskiwania wegglowodorów $w$ warunkach ladowych i morskich. Wydanie konferencyjne. Prace Naukowe Instytutu Nafty i Gazu nr 182, Kraków 2012, s. 239-244.

[4] Jędrzejowska-Tyczkowska H., Bartoń R., Leginowicz A.: Metodyka oceny szczelinowatości węglanowych utworów dewonu Polski poludniowo-wschodniej na podstawie zintegrowanej

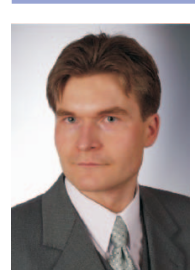

Dr inż. Robert BARTOŃ

Adiunkt w Zakładzie Sejsmiki.

Instytut Nafty i Gazu - Państwowy Instytut Badawczy ul. Lubicz $25 \mathrm{~A}$

31-503 Kraków

E-mail: robert.barton@inig.pl interpretacji danych geologicznych i geofizycznych $w$ rejonie otworu Trzebownisko-3. Nafta-Gaz 2005, nr 9, s. 380-388.

[5] Lynn H., Narhari S.R.,Al-Ashwak S., Kidambi V.K.,Al-Qadeeri B., Al-Khaled O.: PP azimuthal-amplitudes and acoustic impedance for fractured carbonate reservoir characterization. Conference SEG 2010, Denver, Annual Meeting, s. 258-262.

[6] Lynn H.B.: Fracture densities and fracture azimuths evident in the azimuthal amplitudes from the top of a fractured carbonate oil reservoir. Conference SEG 2014, Denver, Annual Meeting, s. 341-345.

[7] Lynn W.: Azimuthal Interval Velocity Uncertainty. Conference SEG 2011, San Antonio, Annual Meeting, s. 279-283.

[8] Zheng Y.: Seismic Azimuthal Anisotropy and Fracture Analysis from PP Reflection Data. Thesis, Calgary, Alberta, March 2006.

Mgr inż. Aleksander WILK

Główny specjalista inżynieryjno-techniczny w Zakładzie Sejsmiki. Instytut Nafty i Gazu - Państwowy Instytut Badawczy

ul. Lubicz 25 A

31-503 Kraków

E-mail: wilka@inig.pl 